\title{
The impact of energy prices on the sustainability of urban transport
}

\author{
P. Amrusch \& F. Wirl \\ University of Vienna, Austria
}

\begin{abstract}
This paper is motivated by the recent strong energy price increases and investigates the impact of these recent price increases on the demand and the composition of urban transport (public and private). In the first section, the relative price change of private transportation due to fuel prices is estimated for Vienna, whereby the substitutability between public and private transport is investigated. In the second section, changes in consumer behaviour related to the fuel efficiency of cars are discussed. In particular, the paper tries to quantify the impact of these price changes on the relative prices in the used-car market.

Keywords: fuel price increase, urban transport, marginal willingness to pay for car efficiency, hedonic mode, used-car market, car model fashion, SUVS.
\end{abstract}

\section{Introduction}

The 2005 mid-year oil price trend reveals the highest nominal increase - of over $\$ 40$ per barrel; only the energy price hikes $1973 / 74$ and $1979-81$ show a similar magnitude (higher in \%, lower in \$s). Fig. 1 shows the oil price evolution in nominal and real terms. Although oil prices have come down in the last month (January), forward prices continue to increase (OPEC [1]).

The product prices (in Rotterdam) reached during 2005 a situation that the prices of diesel surpassed that of gasoline due to the switch to much more efficient diesel engines. This is also shown at the pump (Fig. 2) although not completely due to a still tax advantage for diesel in Austria.

The major goal of this investigation is to trace the behavioural consequences of this price increase in the transport sector with special emphasis on Austria. Since car fuel efficiency affects the cost of operating a car, energy-saving 
behaviour of consumers is reflected in the reduced purchases of petrol-run cars, and the choice of private versus public transport modes.

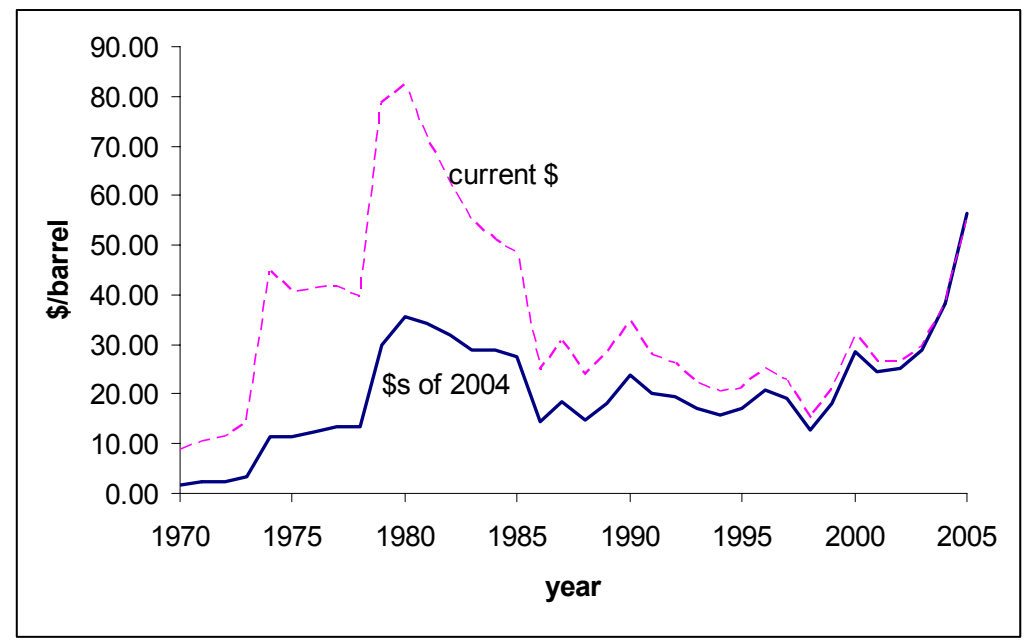

Figure 1: $\quad$ World oil prices since 1970 (BP 1970-2004, IEA for 2005).

The paper is organized as follows: Section 2 sketches background information about some specific characteristics of transport in Austria and in Vienna. Section 3 describes and discusses some key statistics associated with the above mentioned oil and energy price hike. Section 4 uses data from the used car market to estimate empirically the effect of higher fuel costs on the relative prices of large and less fuel efficient cars to smaller and more efficient cars.

\section{Transport in Austria}

The numbers of passengers using public means of transport in Vienna, the only Austrian city with an underground system reached a peak position of 740 million passengers in 2005 - about 5 million $(+0.68 \%)$ commuters more than in the year before (e.g. Wiener Stadtwerke [2]) considering that in Vienna the price of public transport has been constant since 2002 (VOR [3]).

On the other hand, as data on vehicle registration obtained from the database of "Statistik Austria" [4] demonstrate, the passenger car registrations declined in Vienna -5.09\% in 2005 (from 4227 cars in December 2004 to 4012 cars in December 2005), whereas the overall rise of cars registered in Austria amounted to $6.75 \%$ (1195 cars) for the same period. This development indicates a possible substitution effect between private and public transport in 2005 when fuel prices extended their plus from $€ 0.802$ to $€ 0.941$ per litre for diesel and $€ 0.913$ to $€ 1.004$ per litre gasoline, respectively, in relation to 2004 (Fig. 2) (Österreichischer Automobil-, Motorrad- and Touring Club (ÖAMTC) [5]). 
According to car retailers [6, 12, 16], energy-saving behaviour regarding operative costs of cars in December 2005 is also reflected in the higher demand for smaller and more efficient cars, most notably in December 2005. Moreover, smaller-sized cars are advantageous when considering the scarcity of parking in certain districts of Vienna [6]. A possible substitution effect between passenger cars and motorcycles can be observed as well [7]: The increase in newly registered motorcycles of about $222.22 \%$ in December 2005 compared to December 2004 is indicative of a substitution of motorcycles for passenger cars in Vienna, whereas in Austria the overall number of registered motorcycles declined by $7.93 \%$, which highlights a peculiarity of urban areas (Statistik Austria [4]).

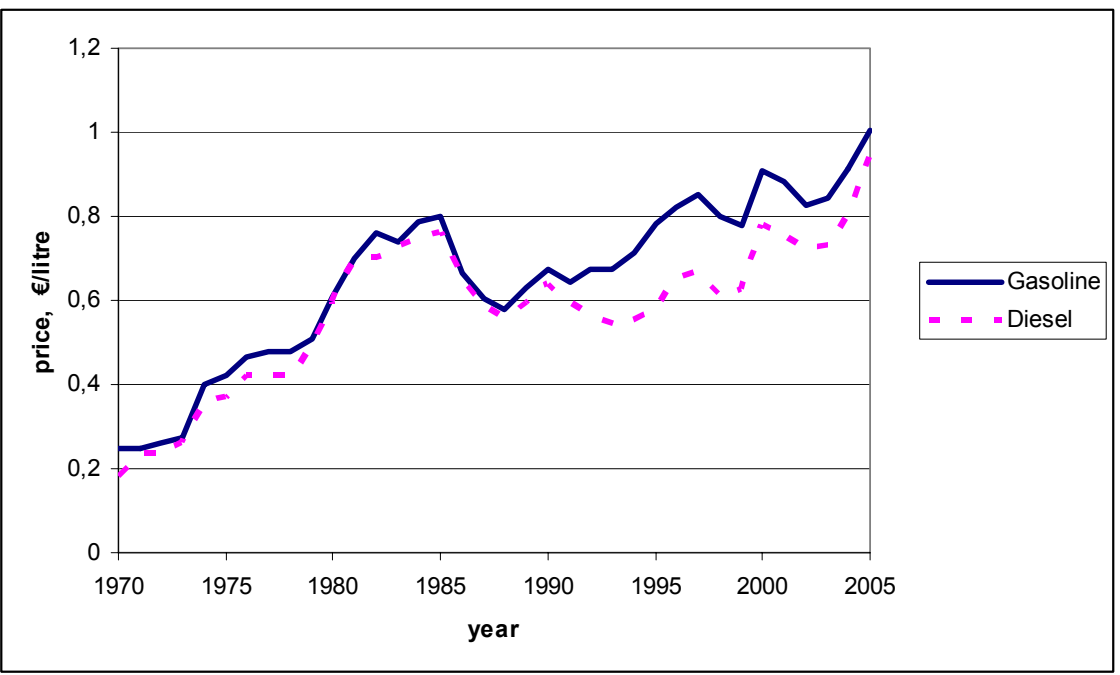

Figure 2: $\quad$ Austrian gasoline and diesel price development (1970-2005).

In February 2006 in relation to December 2005 passenger car registration in Vienna rose again - exhibiting a plus of around $5.39 \%$ in comparison with December 2005, whereas the increase for Austria was about $10.19 \%$. Correspondingly, the number of newly registered motorcycles declined on average by $64.36 \%$ in February 2006 with respect to December 2005. On the other hand, the proportion of gasoline cars declined $17.75 \%$ in Vienna in the same period. However, an additional question concerning future research can be posed: "Did consumers reduce energy-saving behaviour after energy prices stabilized?" To a certain extent we will attempt to go into this issue.

Researchers of the "traffic club Austria" (Verkehrsclub Österreich (VCÖ)) observe that, on one hand public policy attempts to boost the use of public transport, and, on the other hand, the construction of a number of multi-storey car parks is planned [8]. Consequently, public policy will have a mixed and presumably modest impact on the substitution between public and private modes of transport. 


\section{Aggregate effects of 2005 price increases}

It has to expected and is confirmed by car retailers [e.g. 6, 12, 16] that consumers save fuel costs by choosing (horse) power and the construction size and mode of the car or the model. Hence, fuel-saving behaviour is also revealed by the average size of newly registered car models in 2005: New vehicle registration statistics (2004-2005) demonstrate the relative high number of "smaller-sized" compared with 'larger-sized' cars in December 2005 with respect to December 2004 in Vienna [9]:

The market share of the "larger-sized" most popular car model Volkswagen Sharon in 2004 decreased by $3 \%$ in 2005 , whereas the most popular "smallersized" car model Volkswagen Golf Plus advanced by $6 \%$, gaining the leading position among the 50 newly registered car models (and brands) of Austria in 2005. Moreover, the larger-sized model Volkswagen Bus, which occupied the $11^{\text {th }}$ position among Austrian predominantly registered passenger car models in 2004 was out of the classification of the fifty top-selling car models in Austria in 2005. Correspondingly, the Chrysler Voyager, Seat Alhambra and Peugeot 807 lost their position among the top fifty registered cars in 2005.

Moreover, consulting the database of "Statistik Austria" [4] we found that all registered passenger cars with more than 250 kilowatts (KW) showed a $46.67 \%$ decrease in 2005 with respect to 2004.

These results seem contrary to the market strategy 'bigger is better' and the by car magazines [e.g. 11] predicted continuing popularity of sporty - at least "sporty looking" cars like a sport utility vehicles (SUVs) or cross country car (CCVs) also reflected in the recent market sales figures of the market segment sport utility vehicles (SUV) that are still also expected to grow in 2006, respectively (e.g. Espey and Nair [10]).

However, the "sporty" gasoline engine cars of the brand name "Maserati" lost their 100\% market share in terms of car registration in Vienna from December 2005 to February 2006, whereas the smaller-sized also "sporty" gasoline-run car of the brand name "MG". Hence, there is an increased trade-off between fashion and efficiency. Moreover, In February 2006 with respect to December 2005 the demand for "smaller-sized" cars intensified regarding diesel cars in Vienna: The brands Lexus and Rover with cars of predominantly greater-size lost $100 \%$ market share, whereas the small 'Micro Compact Car' experienced the strongest increase in market share by $500 \%$. Figures show that the second leader in market share increase was the "mass car" Hyundai with a plus of $246 \%$ [4]. One might argue that these car models are not comparable since income and preferences have to be assumed identical regarding. However, these observations can give a general overview of car market activities. To monetarize values of single car attributes the hedonic model will provide more detailed insights in the next section, while the hedonic model estimating the marginal willingness to pay for efficiency (and not only the marginal effect) also requires assumptions e.g. on preferences and income (e.g. Freeman [17]).

Even though the high energy prices reduced the price difference between diesel and gasoline, used-car sellers consider Austria to be a "diesel country" 
with around $70 \%$ of cars running on diesel. More than half of the passenger cars in Austria ran on diesel in $2005[12,13]$. In Austria the overall increase in newly registered diesel cars was about $12.07 \%$ in December 2005 with respect to December 2004 (Statistik Austria [4]).

This development is reflected on the use-car market: For instance, 3 of 113 used-cars for sale at Mercedes-Benz dealer in Vienna were gasoline run in March 2006, and all were cabriolets. Other used-car sellers experienced an impossibility of selling gasoline run cars (particularly of larger sized cars) in comparison to diesel cars, i.e. the stock of "Rainer Kraftfahrzeughandels AG" has a Land Rover of the type Red River with a gasoline engine that has remained unsold for 3 years, which is a particularly long period compared to the average time for selling used cars [6].

\section{Empirical quantification for used cars}

The hedonic methodology applied in the automobile sector can be traced back to A. T. Court (1939) "Hedonic Price Indexes with Automotive Examples", in The Dynamics of Automobile Demand, New York 1939 and was formalized by Rosen (1974) [14].

We focus on the used-car market, in which, by assumption, changes in consumer demand for energy-efficient private cars are better reflected due to the various discounts sellers offer on "new" cars to be competitive. Furthermore, contrary to private car sellers, used-car sellers do not deviate significantly from the actual transaction prices proposed by the EUROTAX (the listing of average repurchasing and selling prices for a particular car model). Thirdly, the selling prices of commercial sellers on the used-car market are assumed to be less biased than of private sellers due to the used-car warranty imposed that commercial sellers have to offer by law (Statistik Austria [4]).

The selling prices on the private used-car market show a greater variation than the commercial used-car market (Statistik Austria [4]). The motivation for selling a car may differ, since the commercially sold cars underlie a warranty imposed by law. Hence, the promised and advertised qualities of a car are more credible of commercial sellers due to warranty associated with a transaction.

Another crucial reason for investigating the used-car market and not the market for new car is the fact that, in practice, new cars are sold at a discount rate to enhance competition among sellers, whereas sellers of used and new cars consider the "new car market" as less transparent. Transparency of car attributes and prices, however, is an underlying assumption of the hedonic model. Hence, data on selling prices of only used-cars and more than 100 automotive attributes (e.g. size indicators (number of doors etc.), power (given in kilowatts $(\mathrm{KW})$ ), engine volume (in cubic centimetre (ccm)), age (in months), kilometres driven $(\mathrm{km})$ and other characteristics) are obtained from advertisements published in Motor Bazar in December 2004 and December 2005. Further technical data, such as fuel consumption (in litre $/ \mathrm{km}(1 / \mathrm{km})$ ) standing for the energy efficiency of car models are acquired from other sources (e.g. the VCÖ or car manufacturers). 
Similarly to Atkinson and Halvorsen [15] who included a dummy variable to define the characteristic "luxury car", we constructed dummy variables for the premium segment (e.g. brands as BMW, Mercedes, Porsche) and constructed dummy variables distinguishing subtypes of cars within the premium class, e.g. expensive and less expensive by model. Furthermore, dummy variables for cabriolet, coupe, cross country vehicle or sport utility vehicle, limousine, estate car and van are defined. (in collaboration with experienced used-car sellers (e.g. [16]) and on the basis of the collected automotive attributes cars represent). The random sample of 143 used-cars (108 observations for December 2004, 35 observations for December 2005) consists of 66 limousines, 35 CCVs or SUVs, as well as 22 estate cars, 12 cabriolets, 7 coupes and 1 van, whereas the sample for 2004 includes $31 \mathrm{CCVs}$ or SUVs, 46 limousines, 15 estate cars, 7 cabriolets etc. Surprisingly, the average selling prices of a used-car amounts to $€ 20000$ in the 2004 sample, whereas a used-car in the 2005 sample costs around $€ 14000$. A possible explanation could be that a smaller number of "expensive" or "largersized" car models were offered in 2005 with respect to 2004.

Since cars are considered aggregations of attributes, the hedonic price function relates the price of a car to its attributes by equating the marginal utility of each "car attribute" to the marginal price of this attribute.

Table 1: $\quad$ Hedonic model (December 2004 and December 2005).

\begin{tabular}{|l|c|}
\hline Constant and variables & Coefficients \\
\hline Constant & 10.199 \\
Fuel consumption (litre/km) & $(59.1)$ \\
& -.092 \\
KW (Kilowatt) & $(5.0)$ \\
& .01 \\
Non-premium segment & $(10.4)$ \\
& -.033 \\
CCV or SUV & $(4.7)$ \\
& .421 \\
Kilometres $(\mathrm{km})$ & $(5.2)$ \\
& $-6.75 \mathrm{E}-06$ \\
& $(9.8)$ \\
\hline $\mathrm{R}^{2}=0.79$, Adj. $\mathrm{R}^{2}=0.78, \mathrm{JB}=0.96$, Number of observations $=143$. & \\
Dependent variable: $\ln ($ selling price in $€$ ). & \\
\hline
\end{tabular}

Using OLS, the estimated hedonic regression for the whole sample (December 2004, December 2005) is presented in table 1 and the hedonic regressions for December 2004 and 2005 are given in table 2 along with the absolute t-statistics in parenthesis. All models are estimated with White's heteroscedasticity consistent standard errors. Car characteristics that are highly correlated with other attributes are not included in the regressions e.g. dummy variables created for diesel cars or gasoline cars correlated with fuel 
consumption (indicated in litre per kilometre) were eliminated. Performing the Jarque-Bera test, normality of residuals cannot be rejected. Many authors (i.e. Goodman [18], Cassel and Mendelsohn [21], Halvorsen and Pollakowsky [19], Cropper et al. [20]) have stressed that theory does not suggest an appropriate functional form for hedonic regressions We used the in models of hedonic relationship frequently applied log-lin form (e.g. Freeman [17]). The fitting of this functional form (reported in table 1) explains about $74 \%$ of the variance in $\ln$ (selling price). All coefficients are highly significant at a $95 \%$ confidence interval. As expected, the negative coefficient of fuel consumption implies that an increase in fuel consumption by $1 \mathrm{l} / \mathrm{km}$ reduces selling prices of the car by about $9.9 \%$ - leaving other explanatory variables unaffected. Nonpremium-segmented car brands cost about 3.3\% less than mass car brands. An additional kilowatt costs raises the selling price by about $1.1 \%$. Cars constructed as SUVs or CCVs increase in the selling price around $42.1 \%$. As expected, the mileage of a car (in "kms" driven) negatively affects the selling price. Considering the 2 sub-samples for 2004 and 2005, respectively, the Chow Test (table 2) indicates significant differences in parameters between December 2005 and 2006. Hence, the sample is now divided into 2 separate samples and table 3 presents the two hedonic regressions for 2004 and 2005 separately using heteroscedasticity-consistent standard errors.

Table 2: $\quad$ Chow Break-Point Test.

\begin{tabular}{|ll|ll|}
\hline F-statistic & 2.142738 & Probability & .053279 \\
Log likelihood ratio & 13.42998 & Probability & .036694 \\
\hline
\end{tabular}

Table 3: $\quad$ Hedonic regressions for December 2004 and 2005.

\begin{tabular}{|c|c|c|c|}
\hline \multicolumn{2}{|c|}{ Model 2004} & \multicolumn{2}{|c|}{ Model 2005} \\
\hline Constant, variables & Coefficients & Constant, variables & Coefficients \\
\hline Constant & $\begin{array}{c}10.41449 \\
(46.4)\end{array}$ & Constant & $\begin{array}{r}9.940771 \\
(32.9)\end{array}$ \\
\hline Fuel consumption & $\begin{array}{c}-.0065981 \\
(3.2)\end{array}$ & Fuel consumption & $\begin{array}{r}-.170987 \\
(3.5)\end{array}$ \\
\hline KW & $\begin{array}{l}.008657 \\
(8.8)\end{array}$ & KW & $\begin{array}{r}.014527 \\
(5.6)\end{array}$ \\
\hline Non-premium s. & $\begin{array}{c}-.442782 \\
(4.7)\end{array}$ & Non-premium s. & $\begin{array}{r}-.221502 \\
(2.2)\end{array}$ \\
\hline $\mathrm{Km}$ & $\begin{array}{l}-7.67 \mathrm{E}-06 \\
(7.7)\end{array}$ & $\mathrm{Km}$ & $\begin{array}{c}-5.26 \mathrm{E}-06 \\
(1.9)\end{array}$ \\
\hline CCV, SUV & $\begin{array}{l}-.283976 \\
(3.6)\end{array}$ & CCV, SUV & $\begin{array}{r}.675576 \\
(3.3)\end{array}$ \\
\hline \multicolumn{2}{|c|}{$\begin{array}{l}\mathrm{R}^{2}=.79, \text { Adj. } \mathrm{R}^{2}=.78 \\
\mathrm{JB}=4.1 \\
\text { Number of observations: } 108\end{array}$} & \multicolumn{2}{|c|}{$\begin{array}{l}\mathrm{R}^{2}=.75, \text { Adj. } \mathrm{R}^{2}=.70 \\
\mathrm{JB}=.05 \\
\text { Number of observations: } 35\end{array}$} \\
\hline \multicolumn{4}{|c|}{ Dependent variable: $\ln ($ selling price in $€)$} \\
\hline
\end{tabular}


The coefficients in table 3 have the same signs as in table 1 . However, it is very interesting that the implicit marginal price of fuel consumption has changed in 2005 with respect to 2004. Buyers of cars are willing to pay around $17.1 \%$ more for a reduction in fuel consumption by 1 litre $/ \mathrm{km}$. This accounts for an average rate of $16.4 \%$ in the year of peak energy prices with respect to the previous year. However, also the previously mentioned fashion trend predicted by car magazines is reflected by an increase in the implicit marginal price of CCVs and SUVs increased by around $40 \%$.

On the other hand, the price effect of cars in the premium segment has declined by halve in 2005 . Of course, buyers of cars attach still importance to power expressed in KW and this effect has even increased. On the other hand, the penalty for the mileage of a car is reduced for 2005 compared with 2004 , probably due to ongoing quality improvement cars.

\section{Final remarks}

The empirical study demonstrates that the increase in the marginal willingness to pay for fuel reduction was substantial in the year fuel prices reached their highest nominal peak (2005) compared to the year before. Additionally, car registration numbers in Vienna declined in the year 2005, while the numbers of passengers using public means of transportation and the number of registered motorcycles reached a peak.

Although car magazines expected an augmented demand for SUVs and CCVs, according to new car registration statistics in Vienna the market share of smaller-sized cars increased considerably in conjunction with the number of diesel run cars in 2005 and in the beginning of 2006, respectively. However, it does not mean that "sporty" brands (car models) are not in demand as the latest registration statistics reveal.

According to the empirical estimation conducted above, a similar effect is observable on the used-car market, whereby the marginal willingness to pay for efficient cars increased substantially along with a boost in the marginal willingness to pay for SUVs and CCVs. Hence, the impact of fuel economy on the car market is considerable - surprisingly accompanied by the fashion of CCVs and SUVs on the used-car market. However, the market shares of "new models" also show an increased demand for "smaller", more efficient and diesel run cars along with a decrease in gasoline run CCVs and SUVs.

The conclusions drawn from this paper are not only of particular importance for the public sector (e.g. regarding the construction of public facilities) but also for the private sector (e.g. car manufacturers or energy suppliers).

This study could be amplified to other cities to reflect regional differences, e.g. incorporating effects of public transportation into more detail (e.g. where substitutability is not possible) or to other countries to reveal possible effects of differences in purchasing power. 


\section{References}

[1] OPEC Secretariat: Monthly Oil Report. www.opec.org

[2] Wiener Stadtwerke Holding AG (ed.). Wiener Stadtwerke 24 Stunden für Wien, N. 177. Bohmann Druck und Verlag GmbH \& CoKG, March 2006. http://www.wienerlinien.at/wl/wlinien/jsp/home/guestHome.jsp

[3] Aumann, G., Personal communication, 1 February 2006, Tariffs and Finance department, Verkehrsverbund Ost-Region.

[4] Statistik Austria. http://www.datafact-online.at/

[5] Österreichischer Automobil-, Motorrad- \& Touring Club (ÖAMTC). www.oeamtc.at

[6] Ertl, Martin, Personal communication, 8 February 2006, Sales department of car components, Rainer Kraftfahrzeughandels AG.

[7] Bundesanstalt Statistik Österreich. www.statistik.at/cgibin/presseprint.pl?INDEX $=2005005751$

[8] Frey, H., Personal communication, 9 March 2006, Verkehrsclub Österreich (VCÖ). www.vcoe.at

[9] Zulassungsstatistik (registration statistics). www.autobiz.at

[10] Espey, M., Nair, S., Automobile Fuel Economy: What is Worth? Contemporary Economic Policy, 23(3), pp. 317-323, 2005.

[11] Motor Presse Stuttgart GmbH \& Co KG. Auto, Motor und Sport, 03. 2006.

[12] Kupfer, G., Personal communication, 6 March 2006, Sales department, Mercedes Benz - Wiesenthal \& Co Donaustadt GmbH.

[13] Der Standard, Ölpreis klettert weiter, Diesel kaum noch billiger als Benzin., Standard Verlagsgesellschaft mbH, Wien, pg. 17.17, 28.7.2005.

[14] Rosen, S., Hedonic Prices and Implicit Markets: Product Differentiation in Pure Competition, Journal of Political Economy 82, pp. 34-55, 1974.

[15] Atkinson, S. E. \& Halvorsen R. A New Hedonic Technique for Estimating Attribute Demand: An application to the Demand for Automobile Fuel Efficiency. The Review of Economics and Statistics 66, pp. 417-426, 1984.

[16] Matzenauer, H., Personal communication, Sales department, Autohaus Stipschitz GmbH, 7 February 2006.

[17] Freeman, M. C., The Measurement of Environmental and Resource Values, Theory and Methods, Resources for the Future: Washington, DC, 2003.

[18] Goodman, A. C., Hedonic Prices, Price Indices and Housing Markets, Journal of Urban Economics 5(4), pp. 471-484, 1978.

[19] Halvorsen, R. \& Pollakowsky H.O., Choice of Functional Form for Hedonic Price Equations. Journal of Urban Economics 10(1), pp. 37-49, 1981.

[20] Cropper, M. L., Deck, L.B. \& McConnell, K.E., On the Choice of Functional Form for Hedonic price Functions. Review of Economics and Statistics 70(4), pp. 668-232, 1988. 
662 Urban Transport XII: Urban Transport and the Environment in the 21st Century

[21] Cassel, E. \& Mendelsohn R., The Choice of Functional Forms for Hedonic Price Equations: Comment. Journal of Urban Economics, 18, pp. 135-142, 1985. 